02

\title{
Сравнительные исследования фотофизических свойств димегина, фотодитазина и радахлорина
}

\author{
() И.В. Багров, А.В. Дадеко, В.М. Киселев, Т.Д. Муравьева, А.М. Стародубцев \\ Государственный оптический институт им. С.И. Вавилова, \\ 199034 Санкт-Петербург, Россия \\ e-mail: kiselevvm21@gmail.com
}

Поступила в редакцию 30.08.2018 г.

Проведено сравнительное исследование фотофизических свойств фотосенсибилизаторов: димегина, фотодитазина и радахлорина. Для димегина и фотодитазина с применением двух методик измерены квантовые выходы генерации синглетного кислорода и константы тушения синглетного кислорода димегином и фотодитазином, а также квантовый выход флуоресценции димегина.

DOI: $10.21883 /$ OS.2019.02.47198.259-18

\section{Введение}

Информация о фотофизических свойствах фотосенсибилизаторов для фотодинамической терапии и флуоресцентной диагностики имеет большое практическое значение. Поэтому исследования этих свойств активно ведутся $[1-10]$, в том числе и по отношению к димегину, фотодитазину и радахлорину. Основными фотофизическими свойствами фотосенсибилизаторов, определяющими их фотодинамическую активность, являются эффективность генерации синглетного кислорода и его время жизни в исследуемой среде. Для флуоресцентной диагностики актуальна интенсивность флуоресценции фотосенсибилизатора, обозначающая границы и размеры патологического образования. Исследование этих фотофизических свойств димегина как фотосенсибилизатора, проводимое в настоящей работе, в сравнении со свойствами фотодитазина и радахлорина, уже применяемыми в медицинской практике, позволит выявить наиболее перспективные и конкурентоспособные свойства димегина как фотосенсибилизатора для определения степени его пригодности в области фотодинамической терапии.

\section{Материалы и методика эксперимента}

При проведении исследований в качестве фотосенсибилизаторов применялись димегин и фотодитазин в виде лиофильно высушенных порошков, изготовленных в Институте биохимии имени А.Н. Баха, РАН, и радахлорин в виде водного 0.35\%-раствора для внутривенного введения „Радахлорин $® “$ („Рада-Фарма“, Москва). В качестве фотосенсибилизаторов сравнения при измерениях применялись краситель метиленовый синий, протопорфирин IX (Sigma-Aldrich) и фуллерен С 60 (ЗАО „ИЛИП“, Санкт-Петербург). В качестве ловушки синглетного кислорода использовался триптофан (L-триптофан), аминокислота, НИЦ, серия 110302 (Sigma-Aldrich).

В качестве растворителей фотосенсибилизаторов в процессе исследований использовались дистиллирован- ная вода, фосфатный буфер (водный раствор $\mathrm{Na}_{2} \mathrm{HPO}_{4}$ и $\mathrm{K}_{2} \mathrm{HPO}_{4}$, pH 7.0 и 7.4), а также этанол и тетрахлорметан $\left(\mathrm{CCl}_{4}\right)$. Два последних растворителя использовались в основном для прямого наблюдения генерации синглетного кислорода при сравнении эффективности исследуемых фотосенсибилизаторов.

Для изучения фотофизических свойств фотосенсибилизаторов применялись флуоресцентный и спектрофотометрический методы. Источниками оптического возбуждения фотосенсибилизаторов служили светодиодные матрицы серии $\mathrm{HR} 40 \mathrm{E}$ с различными длинами волн излучения и с шириной полосы излучения $\Delta \lambda_{0.5}=20 \mathrm{~nm}$. Излучающая поверхность матриц $26 \times 26 \mathrm{~mm}$. Максимальные значения плотности мощности излучения для используемых светодиодных матриц приведены в табл. 1. Измерение непрерывной мощности излучения светодиодных источников осуществлялось измерителем мощности излучения Coherent-Molectron PS-10. Подводимая электрическая мощность для светодиодной матрицы с $\lambda_{m}=405 \mathrm{~nm}$ равна $50 \mathrm{~W}$, а для матриц с $\lambda_{m}=465,525$ и $625 \mathrm{~nm}$ равна $100 \mathrm{~W}$.

Применялось также созданное в процессе работы устройство с матрицей из четырех светодиодов фирмы „Edison“ (Lamp DC32-34V) с электрической мощностью отдельного светодиода $3 \mathrm{~W}$ и рабочим спектральным диапазоном $\left(\lambda_{m} \approx 395-405 \mathrm{~nm}\right)$, который соответствует пику Cоре и является оптимальным с точки зрения возбуждения исследуемых фотосенсибилизаторов.

Устройство с матрицей из четырех светодиодов фирмы „Edison“(Lamp DC32-34V) для облучения исследуемых растворов фотосенсибилизаторов представлено на рис. 1, $a$. Внутрь этого устройства устанавливается кварцевая кювета $10 \times 10 \times 40 \mathrm{~mm}$ с раствором фотосенсибилизатора. Световая плотность мощности излучения $250 \mathrm{~mW} / \mathrm{cm}^{2}$.

Растворы фотосенсибилизаторов при определении квантового выхода генерации синглетного кислорода с применением метода „химических ловушек“облучались светодиодной матрицей с длиной волны излучения 
Таблица 1. Параметры излучения светодиодных матриц

\begin{tabular}{c|c|c|c|c}
\hline$\lambda_{m}, \mathrm{~nm}$ & 405 & 465 & 525 & 625 \\
\hline$P, \mathrm{~W} / \mathrm{cm}^{2}$ & 0.90 & 1.5 & 0.60 & 1.0
\end{tabular}

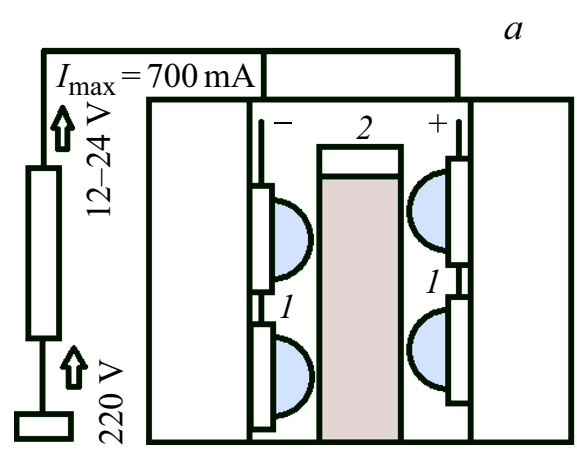

$b$

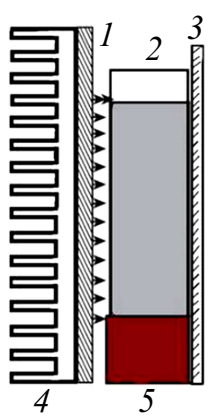

Pис. 1. Схемы устройств для облучения растворов фотосенсибилизаторов: (a) 1 - светодиоды, 2 - кварцевая кювета с раствором фотосенсибилизатора; (b) 1 - светодиодная матрица, 2 - кварцевая кювета с раствором фотосенсибилизатора, 3 алюминиевое зеркало, 4 - радиатор охлаждения матрицы, 5 - подставка.

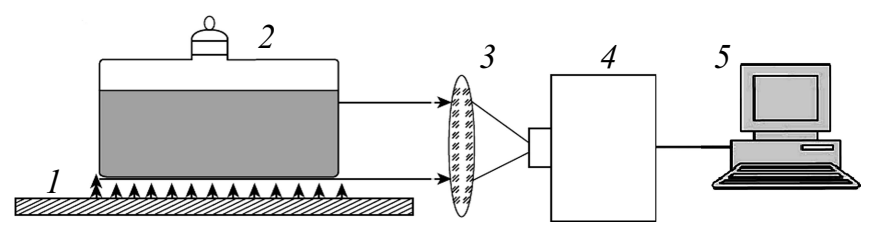

Pис. 2. Схема эксперимента по измерению флуоресценции фотосенсибилизатора и генерации СК: 1 - светодиодная матрица, 2 - колба с раствором фотосенсибилизатора, 3 линза, 4 - спектрометр, 5 - персональный компьютер.

$525 \mathrm{~nm}$ и плотностью мощности $80 \mathrm{~mW} / \mathrm{cm}^{2}$. Схема эксперимента, применявшаяся при облучении исследуемых растворов, представлена на рис. $1, b$. Раствор фотосенсибилизатора (димегин или фотодитазин) совместно с триптофаном был в кварцевой кювете $10 \times 10 \times 40 \mathrm{~mm}$, которая между циклами облучения помещалась в измерительный отсек спектрального прибора для измерения изменения спектра поглощения раствора под воздействием облучения. Изменение спектра поглощения исследуемого раствора химической ловушки под воздействием облучения раствора измерялось с применением спектрофотометра Shimadzu UV-3600.

При регистрации флуоресценции фотосенсибилизатора или люминесценции синглетного кислорода из объема исследуемого раствора в процессе облучения его светодиодной матрицей применялась схема эксперимента из работы [11], которая представлена на рис. 2. В качестве спектральных приборов использовались ИК спектрометры SDH-IV и M-266 с приемной InGaAs-линейкой.
Измерение времени жизни и констант тушения синглетного кислорода выполнялось с применением схемы эксперимента с импульсным источником возбуждения фотосенсибилизаторов, описанной ранее в [12].

\section{Результаты эксперимента и их обсуждение}

Для сравнения фотофизических свойств димегина, фотодитазина и радахлорина прежде всего были измерены спектры оптического поглощения исследуемых фотосенсибилизаторов, растворы которых для димегина и фотодитазина были получены с использованием лиофильно высушенных порошков, а для радахлорина с применением лекарственной формы. Результаты измерений представлены на рис. 3. Как видно из этого рисунка, максимумы поглощения в пике Соре для димегина и фотодитазина практически не отличаются, а для радахлорина поглощение в максимуме несколько ниже, что объясняется его лекарственной формой с нестабильностью состава. Эти результаты неплохо коррелируют с данными, приведенными в работе [9], в которой при одинаковой концентрации димегина и фотодитазина их поглощение в максимуме пика Соре также примерно одинаково.

При анализе спектров поглощения растворов фотосенсибилизаторов следует отметить заметное влияние растворителей на положение максимума в пике Соре и ширину спектрального профиля для каждого фотосенсибилизатора (рис. 4 и табл. 2). Для удобства сравнения этих спектральных профилей они приведены к одинаковому значению максимума в пике Соре. Для димегина в тетрахлорметане значение максимума в пике Соре умножено на 10. Наибольшее уширение профиля поглощения на рис. 4 наблюдается для раствора димегина в тетрахлорметане. Характерный общий подъем этого профиля по отношению к другим кривым объясняется наложением на него крыла поглощения тетрахлорметана

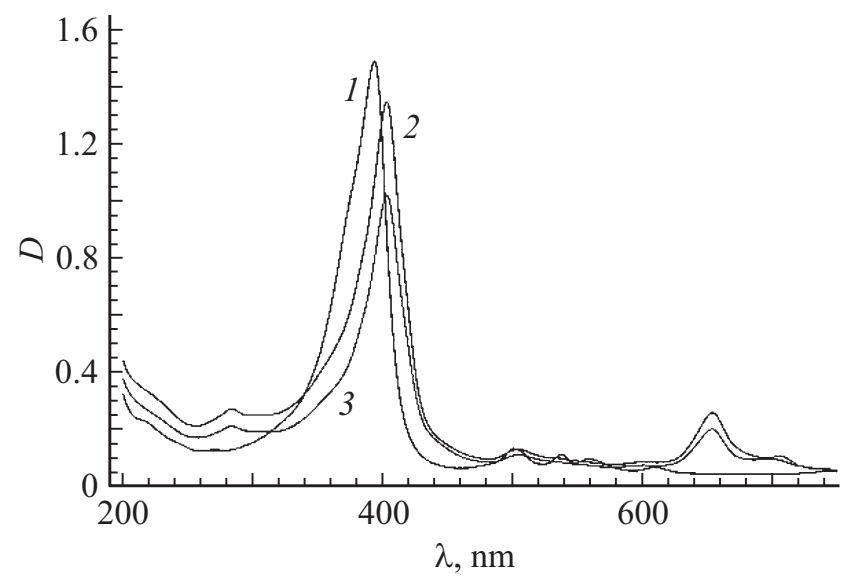

Рис. 3. Спектры поглощения растворов димегина (1), фотодитазина (2) и радахлорина (3) в фосфатном буфере с $\mathrm{pH}$ 7.0. Концентрация фотосенсибилизаторов $-10^{-5} \mathrm{M}$. 
Таблица 2. Положение и полуширина максимума оптического поглощения (пик Соре) для растворов димегина и фотодитазина

\begin{tabular}{c|c|c|c|c}
\hline Фотосенсибилизатор & \multicolumn{3}{|c|}{ Димегин } & \multicolumn{3}{|c}{ Фотодитазин } \\
\hline \multirow{2}{*}{ Растворители } & \multicolumn{3}{|c}{ Спектральные характеристики } \\
\cline { 2 - 5 } & $\lambda_{m}, \mathrm{~nm}$ & $\Delta \lambda_{0.5}, \mathrm{~nm}$ & $\lambda_{m}, \mathrm{~nm}$ & $\Delta \lambda_{0.5}, \mathrm{~nm}$ \\
\hline Вода дистиллированная, $\mathrm{pH} \mathrm{6.0}$ & 391.8 & 45.0 & 405.0 & 34.2 \\
Фосфатный буфер, $\mathrm{pH} 7.0$ & 393.5 & 38.8 & 402.8 & 41.0 \\
Этанол, $\mathrm{pH} 7.6$ & 397.5 & 30.0 & 401.7 & 32.0 \\
Тетрахлорметан $\left(\mathrm{CCl}_{4}\right)$ & 397.5 & 86.0 & 416.4 & 107.3
\end{tabular}

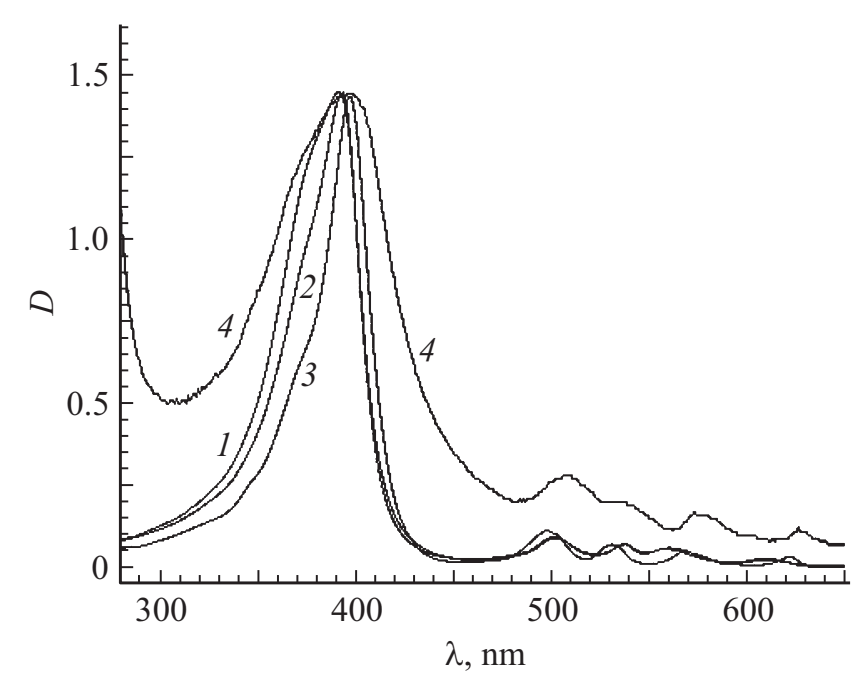

Рис. 4. Спектры поглощения димегина в воде (1), буфере (2), этаноле (3) и тетрахлорметане (4), концентрация димегина в воде, буфере и в этаноле $10^{-5} \mathrm{M}$, в тетрахлорметане $10^{-6} \mathrm{M}$.

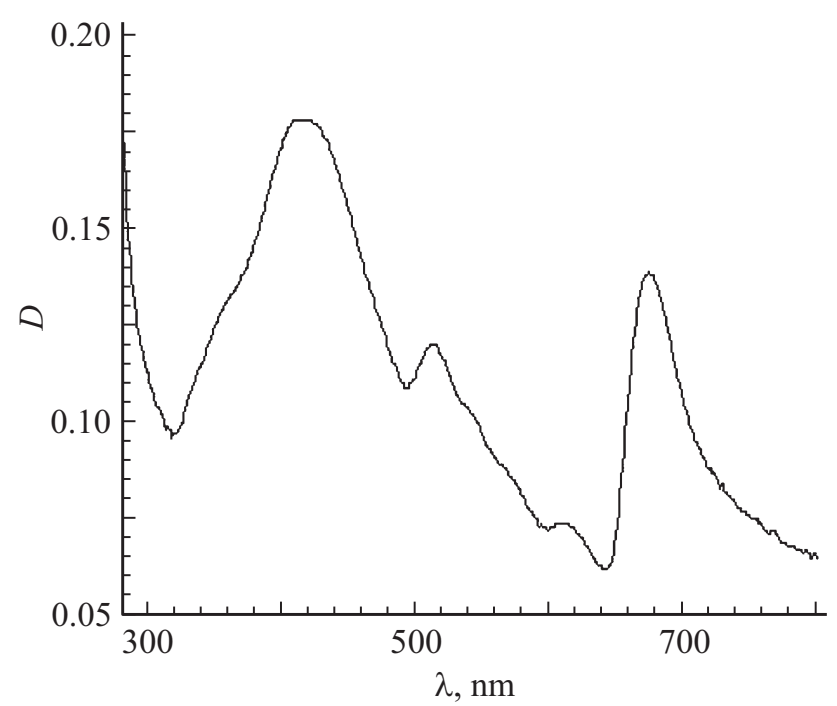

Pис. 5. Спектр поглощения фотодитазина в тетрахлорметане, концентрация раствора $10^{-6} \mathrm{M}$.
$\left(\mathrm{CCl}_{4}\right)$, максимум которого расположен в УФ области спектра на $\lambda_{m}=254 \mathrm{~nm}$ [13]. Еще большее уширение профиля поглощения, как видно из табл. 2 и рис. 5, имеет место для раствора фотодитазина в тетрахлорметане, который также располагается на крыле поглощения растворителя $\mathrm{CCl}_{4}$.

Интересно отметить, что для димегина в фосфатном буфере и в этаноле по отношению к раствору в дистиллированной воде максимумы смещаются вправо, а для фотодитазина, наоборот, максимумы смещаются влево в сторону уменьшения длины волны. В результате в фосфатном буфере и в этаноле максимумы в спектрах поглощения для димегина и фотодитазина сближаются.

Как видно из приведенных рисунков, структура профиля поглощения фотосенсибилизатора заметно меняется при использовании разных растворителей. Как видно из рис. 5 , в растворе фотодитазина в тетрахлорметане меняется и соотношение максимумов в пике Соре и $Q$-максимумах. Максимум в красной области спектра почти выравнивается по высоте с максимумом в пике Cope.

Эффективность генерации синглетного кислорода, нарабатываемого в водных растворах при передаче фотовозбуждения от фотосенсибилизатора кислороду, определялась методом „химических ловушек“ и методом прямой регистрации люминесценции синглетного кислорода на длине волны $1270 \mathrm{~nm}$. При применении метода „химических ловушек“ в качестве ловушки синглетного кислорода был использован триптофан, по изменению концентрации которого в растворе должна была определяться наработка синглетного кислорода. Однако, как показал эксперимент, для исследуемых фотосенсибилизаторов при применении метода .химических ловушек. следует учитывать наряду с понижением концентрации триптофана и эффективное понижение максимума поглощения в пике Соре фотосенсибилизатора, связанное с уменьшением концентрации фотосенсибилизатора в процессе его облучения. Это понижение концентрации фотосенсибилизатора более заметно для раствора фотодитазина и особенно радахлорина. По этой причине эффективность наработки синглетного кислорода также должна уменьшаться и выходить на насыщение, что и демонстрирует рис. 6, на котором показана зависимость эффективности наработки синглетного кислорода (СК) 


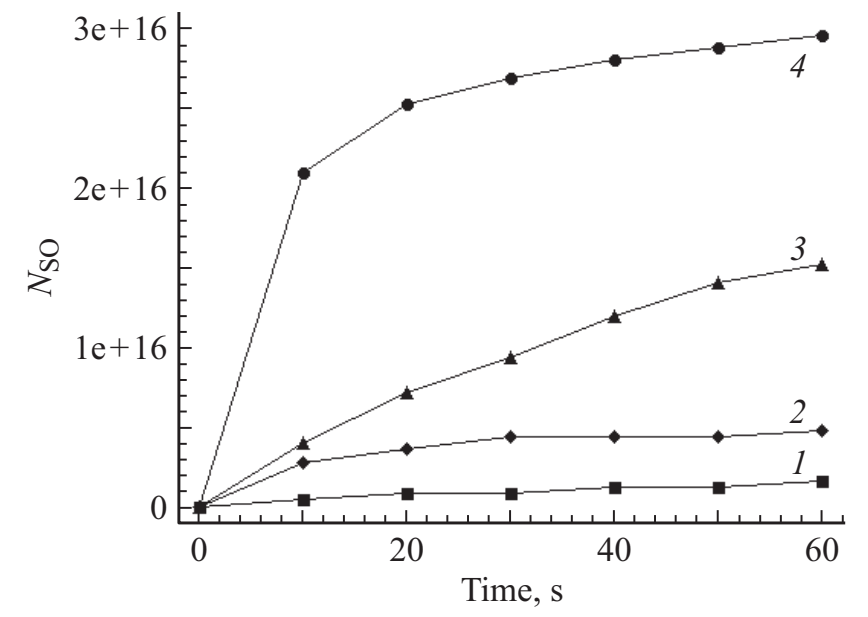

Рис. 6. Зависимость наработки концентрации СК ( $\mathrm{N}_{\mathrm{SO}}$, $\mathrm{mol} / \mathrm{cm}^{3}$ ) от времени облучения растворов радахлорина (1), фотодитазина $(2,4)$ и димегина (3) при концентрации фотосенсибилизаторов $10^{-6} \mathrm{M}(1,2,3)$ и $10^{-5} \mathrm{M}(4)$.

в процессе облучения исследуемых растворов фотосенсибилизаторов.

Как видно из приведенного рисунка, наработка концентрации СК, расходуемого на образование эндоперекиси триптофана, для радахлорина минимальная, что связано с более низким поглощением в пике Соре. Для фотодитазина и димегина на начальном участке облучения наработка примерно одинаковая, однако далее кривые расходятся из-за более быстрого уменьшения концентрации фотодитазина в растворе по сравнению с димегином. Выход на насыщение наработки СК наблюдается для фотодитазина и с более высокой исходной концентрацией $10^{-5} \mathrm{M}$.

Эффективность генерации СК димегином, фотодитазином и радахлорином при облучении их светодиодными матрицами с различными длинами волн излучения представлена в виде числа молекул СК, образующихся при взаимодействии с возбужденной молекулой фотосенсибилизатора (табл. 3). При оценке учитывались оба канала расходования СК: на окисление как триптофана, так и самого фотосенсибилизатора. При этом первое значение по наработке синглетного кислорода, приведенное в таблице, относится к окислению триптофана, а второе значение, приведенное в скобках, соответствует суммарной наработке синглетного кислорода, вычисленной с учетом обоих каналов его расходования.

Эффективность генерации СК с применением прямых методов регистрации наработки СК путем измерения его люминесценции на $\lambda=1270 \mathrm{~nm}$ представлена на рис. 7 при облучении растворов димегина и фотодитазина в дистиллированной воде и в фосфатном буфере с $\mathrm{pH}$ 7.4. Следует заметить, что фосфатный буфер с $\mathrm{pH} 7.4$ соответствует $\mathrm{pH}$ крови, поэтому люминесценция СК в этом растворе близка к той, которая наблюдается в реальной биоткани. Спектры люминесценции СК в водных рас- творах регистрировались с применением монохроматора M266 с временем экспозиции $12 \mathrm{~s}$. Оптическая накачка растворов (25 $\mathrm{ml}$ в стеклянной колбе) выполнялась с помощью светодиодной матрицы на $\lambda=405 \mathrm{~nm}$ с плотностью мощности излучения $0.89 \mathrm{~W} / \mathrm{cm}^{2}$.

Более низкая интенсивность люминесценции СК в растворе фотодитазина связана с уже отмеченным выше заметным уменьшением концентрации фотосенсибилизатора в процессе облучения раствора на временном интервале $10-12 \mathrm{~s}$ и с еще более заметным убыванием концентрации фотосенсибилизатора в фосфатном буфере. Это различие в интенсивности люминесценции СК в растворах димегина и фотодитазина практически отсутствует при использовании в качестве растворителей этанола или тетрахлорметана $\left(\mathrm{CCl}_{4}\right)$, где время экспозиции при регистрации спектров люминесценции, в данном случае с применением ИК спектрометра SDH-IV, намного меньше (на порядок для этанола и более чем на два порядка, для растворов в $\mathrm{CCl}_{4}$ ).

Применимость фотосенсибилизаторов во флуоресцентной диагностике, основанной на способности фотосенсибилизаторов флуоресцировать при облучении светом, тем самым обозначая границы и размеры патологического образования, была оценена определением
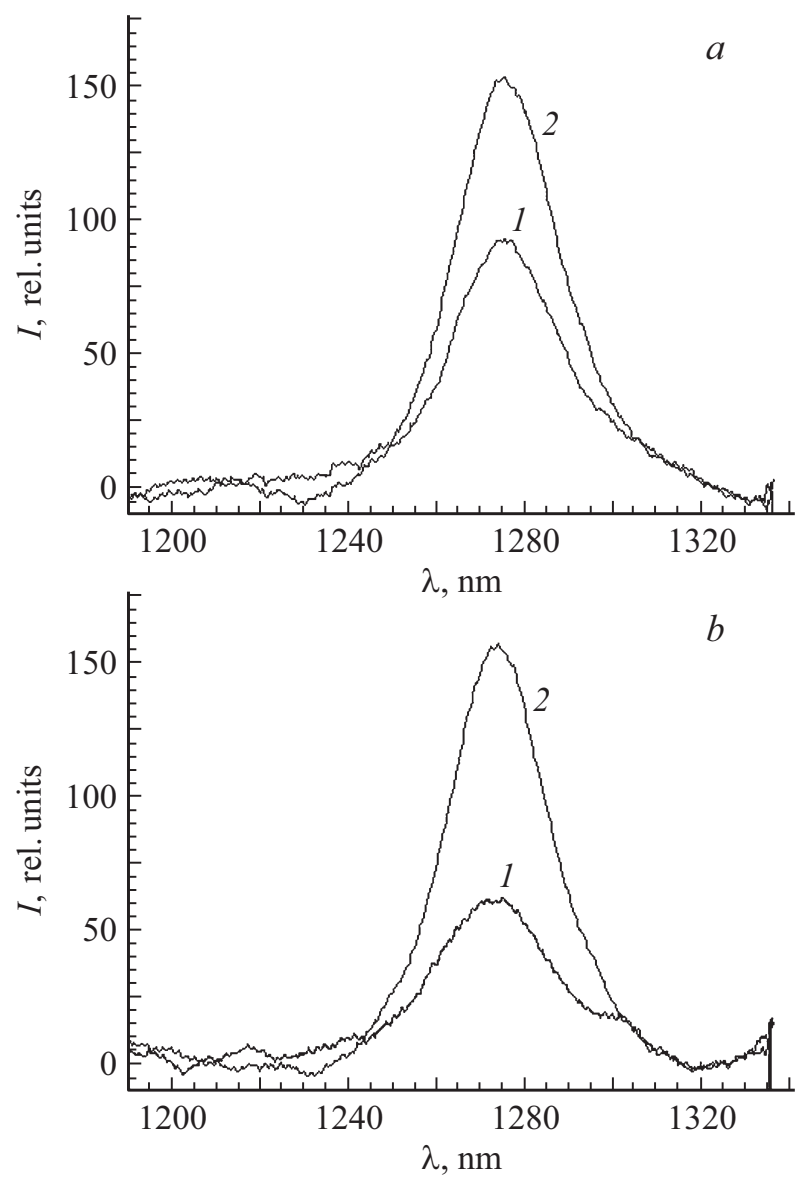

Рис. 7. Люминесценция СК в растворах фотодитазина (1) и димегина $(2)$ в дистиллированной воде $(a)$ и в фосфатном буфере $(b)$, концентрация растворов $10^{-5} \mathrm{M}$. 
Таблица 3. Генерация СК фотосенсибилизаторами, $\times 10^{13} \mathrm{~mol} / \mathrm{cm}^{3} \mathrm{~s}$

\begin{tabular}{c|c|c|c|c}
\hline \multirow{2}{*}{ Фотосенсибилизатор } & \multicolumn{4}{|c}{ Источник облучения } \\
\cline { 2 - 5 } & $\lambda \approx 395 \sim 405 \mathrm{~nm}$ & $\lambda=465 \mathrm{~nm}$ & $\lambda=525 \mathrm{~nm}$ & $\lambda=625 \mathrm{~nm}$ \\
\hline Димегин & $39.2(39.8)$ & $1.1(1.17)$ & $2.3(2.37)$ & $0.5(0.53)$ \\
Фотодитазин & $27.6(32.6)$ & $1.0(1.1)$ & $2.2(2.4)$ & $3.6(4.1)$ \\
Радахлорин & $3.9(5.9)$ & $\sim 0(0.1)$ & $\sim 0(\sim 0)$ & $0.6(0.8)$
\end{tabular}
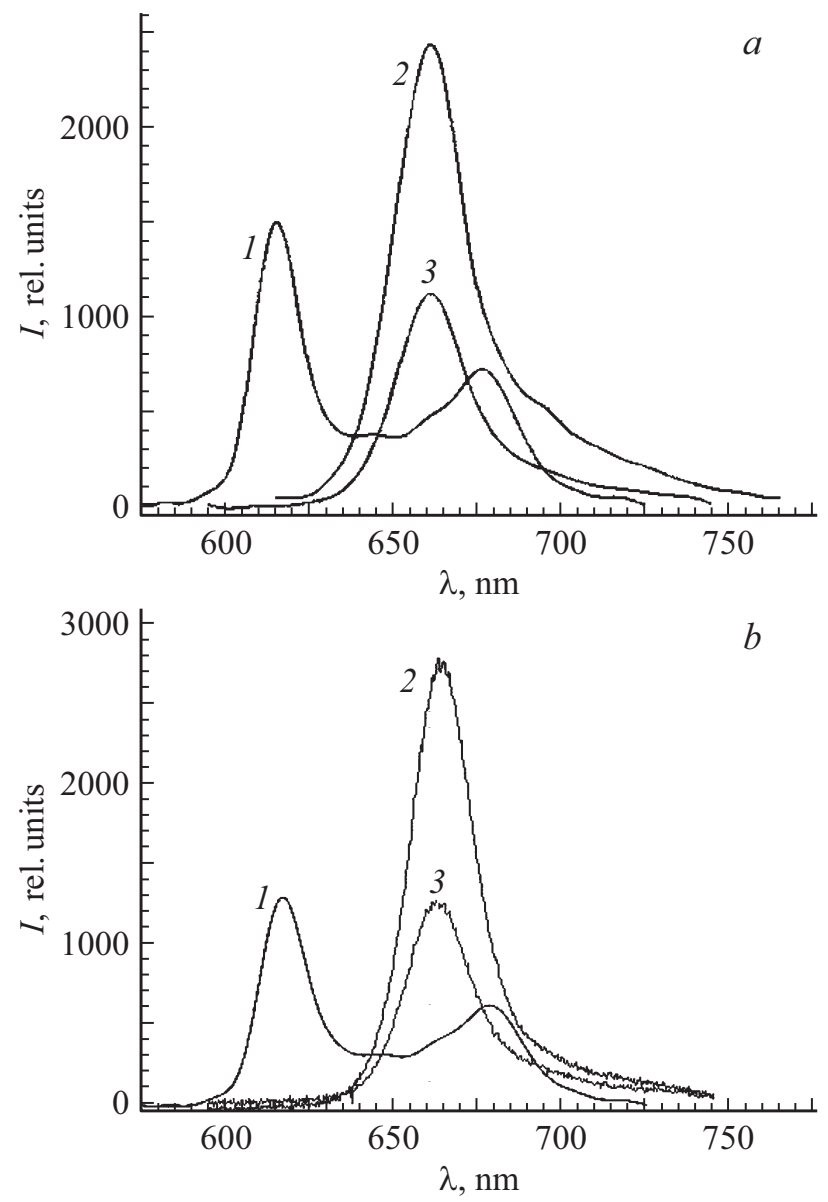

Рис. 8. Спектры флуоресценции димегина (1), фотодитазина (2) и радахлорина (3) для растворов в дистиллированной воде $(a)$ и в фосфатном буфере $\mathrm{pH} 7.4(b)$.

интенсивности флуоресценции изучаемых фотосенсибилизаторов. При одинаковой концентрации димегин, фотодитазин и радахлорин имеют примерно одинаковую флуоресценцию. В качестве примера полученных спектров на рис. 8 приведены спектры флуоресценции трех фотосенсибилизаторов при возбуждении светом с длиной волны $405 \mathrm{~nm}$ для двух растворителей.

При измерении флуоресценции исследуемых фотосенсибилизаторов показано, что спектры флуоресценции имеют две характерные полосы [14], зеркально симметричные двум наиболее длинноволновым полосам поглощения. Для димегина на рис. 9 это показано очень отчетливо, а для фотодитазина, как и для радахлорина, второй максимум представлен только в виде небольшого подъема на крыле основного более высокого максимума. Для удобства сравнения максимумы кривых на рис. 9 приведены к примерно одинаковым амплитудам.

С использованием данных, приведенных на рис. 9, была построена схема энергетических уровней димегина, представленная на рис. 10. Как видно на рисунке, полосы поглощения $(I, I I)$ и флуоресценции $(1,2)$ в спектре димегина принадлежат колебательной структуре
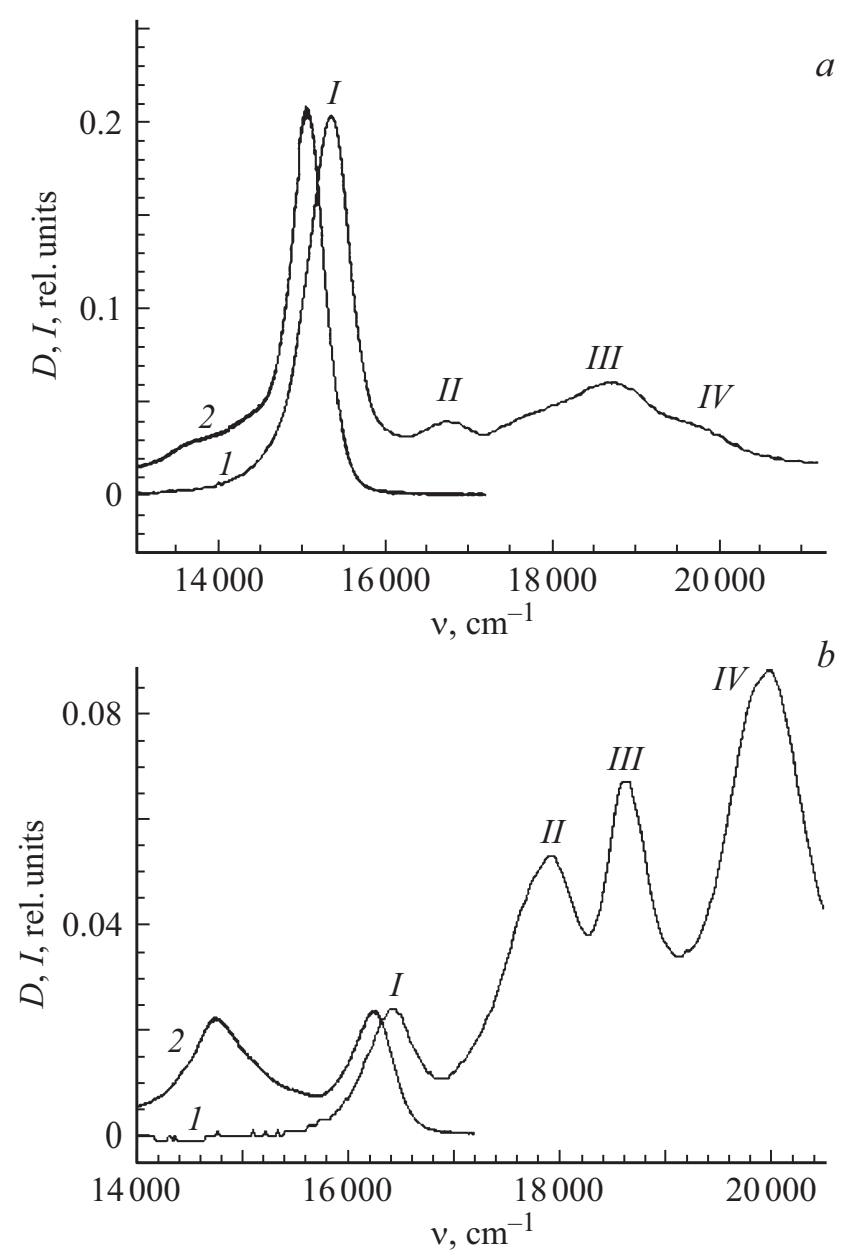

Рис. 9. Зеркальная симметрия спектров поглощения (1) и флуоресценции (2) для растворов фотодитазина $(a)$ и димегина $(b)$ в дистиллированной воде при облучении светодиодной матрицей с $\lambda_{m}=405 \mathrm{~nm}$, концентрация фотосенсибилизаторов $10^{-5} \mathrm{M}$. 


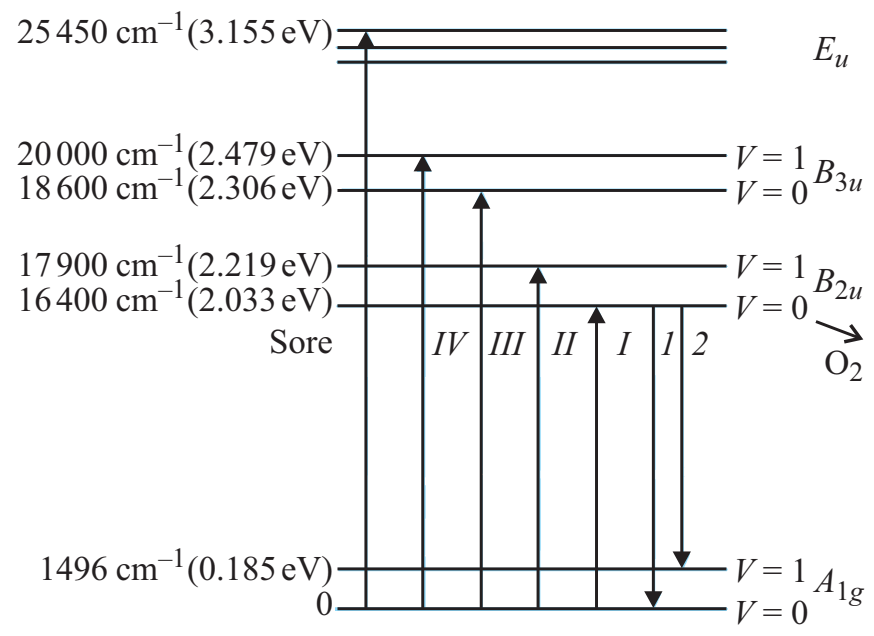

Рис. 10. Схема энергетических уровней димегина.

одного электронного перехода. Аналогично полосы III и $I V$ также принадлежат колебательной структуре одного электронного перехода. Частотный интервал между полосами поглощения $I$ и $I I$, равный $1500 \mathrm{~cm}^{-1}$, что характерно для порфиринов [14], в пределах погрешности эксперимента совпадает с частотным интервалом между полосами флуоресценции $\left(1496 \mathrm{~cm}^{-1}\right)$.

Квантовые выходы СК для димегина и фотодитазина были получены с применением двух методов: метода химической ловушки (триптофана) и метода прямой регистрации люминесценции СК. Для определения квантового выхода генерации СК методом химической ловушки в качестве фотосенсибилизатора сравнения был использован краситель метиленовый синий $\left(\Phi_{\mathrm{MC}}=0.52[15]\right)$, а методом прямой регистрации люминесценции СК фуллерен $\mathrm{C}_{60}(\Phi=0.96[16])$. Поскольку разность между квантовыми выходами генерации СК метиленовым синим и димегином можно представить как разность в расходовании ловушки СК - триптофана, в данном эксперименте применялась следующая формула [17] :

$$
\Phi_{P S}=\frac{\left(c_{0}-c_{t}\right) N_{a} V_{R}}{\left(1-10^{-D}\right) A I t},
$$

где $c_{0}$ и $c_{t}-$ концентрации триптофана в растворе до и после облучения соответственно, $N_{A}$ - число Авогадро, $V_{R}$ - реакционный объем раствора, $D-$ оптическая плотность раствора на длине волны облучения, $A-$ площадь облучения, $I$ - интенсивность облучения, $t-$ время облучения.

Записывая данную формулу для димегина и метиленового синего и взяв их отношение с одновременным сокращением параметров, одинаковых для двух фотосенсибилизаторов в данном исследовании, получим формулу

$$
\Phi_{\Delta D}=\Phi_{\Delta M B} \frac{\left(c_{0 D}-c_{t D}\right)}{\left(c_{0 M B}-c_{t M B}\right)},
$$

по которой был определен квантовый выход генерации СК димегином и фотодитазином, которые составили $0.65 \pm 0.06$ и $0.56 \pm 0.05$ соответственно.

При определении квантового выхода генерации СК путем прямого измерения люминесценции СК выполнялось измерение генерируемой стационарной люминесценции СК в районе длины волны $1270 \mathrm{~nm}$ для двух фотосенсибилизаторов: исследуемого и базового в условиях растворения фотосенсибилизаторов в тетрахлорметане $\left(\mathrm{CCl}_{4}\right)$. Для этих растворов наблюдается более эффективная генерация СК, а кроме того, для них удобнее выполнить с необходимой точностью измерения времени жизни СК, которое в этих растворах на три порядка выше, чем в водных растворах. При этом интенсивность сигнала люминесценции СК может быть описана следующим образом [17]:

$$
I=\gamma k_{r} \tau \Phi\left(1-10^{-D}\right) I_{\mathrm{ex}},
$$

где $k_{r}$ - константа скорости излучательного перехода на длине волны $1270 \mathrm{~nm}, I_{\text {ex }}-$ интенсивность оптического возбуждения, $\gamma-$ постоянный коэффициент, определяемый оборудованием, $\tau-$ время жизни синглетного кислорода в растворе, $D-$ оптическая плотность раствора на длине волны возбуждения, $\Phi-$ квантовый выход генерации СК.

Записав аналогичные выражения для сигнала люминесценции СК для базового и исследуемого фотосенсибилизаторов и взяв их отношение, получим соответствующее выражение для вычисления квантового выхода генерации СК для исследуемого фотосенсибилизатора:

$$
\Phi_{s}=\Phi_{b}\left(\frac{I_{s}}{I_{b}}\right) \frac{\tau_{b}}{\tau_{s}} \frac{\left(1-10^{-D_{b}}\right)}{\left(1-10^{-D_{s}}\right)} \frac{I_{\mathrm{ex} b}}{I_{\mathrm{ex} s}},
$$

где индекс $b$ соответствует базовому фотосенсибилизатору, а индекс $s-$ исследуемому.

В соответствии с этим выражением для вычисления квантового выхода генерации СК для исследуемого фотосенсибилизатора были получены значения интенсивности оптического возбуждения, интенсивности люминесценции, оптической плотности растворов на длине волны возбуждения и времени жизни СК для базового и исследуемого фотосенсибилизаторов. В результате были получены квантовые выходы генерации СК для димегина и фотодитазина $-0.66 \pm 0.06$ и $0.58 \pm 0.05$, коррелирующие со значениями, полученными методом химических ловушек, а также с результатами работы [1]. В свою очередь, квантовый выход генерации СК для фотодитазина хорошо коррелирует с квантовым выходом СК для радахлорина $(0.52-0.62)$, приведенным в работе [18], вследствие их общей хлориновой природы.

В процессе эксперимента при измерении времени жизни СК по экспоненциальному затуханию люминесценции СК, представленному на рис. 11, $a$, были определены также константы тушения возбужденного состояния кислорода в растворе с помощью зависимости, приведенной для раствора димегина на рис. $11, b$. Эти константы оказались равны 

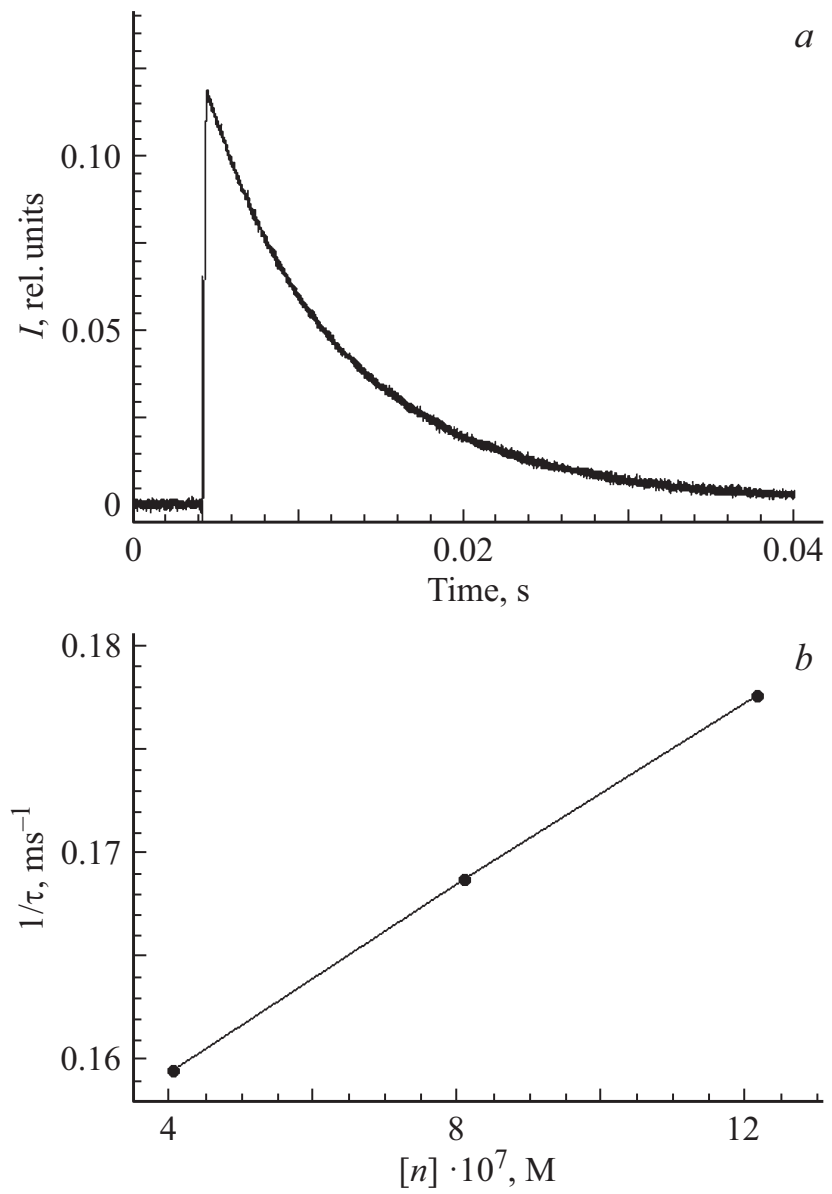

Рис. 11. Затухание люминесценции СК $(a)$ и зависимость скорости тушения СК в растворе от концентрации димегина $(b)$.

для димегина $2.2 \cdot 10^{7} 1 \mathrm{~mol}^{-1} \mathrm{~s}^{-1}$, а для фотодитазина $2.5 \cdot 10^{7} 1 \mathrm{~mol}^{-1} \mathrm{~s}^{-1}$. Поскольку константа тушения возбужденного состояния кислорода в растворе самим растворителем много меньше [19], приведенные значения констант тушения следует отнести к тушению СК самими фотосенсибилизаторами.

Квантовый выход флуоресценции димегина определялся также с применением фотосенсибилизаторасравнения, в качестве которого выступал „Протопорфирин IX“. Спектры флуоресценции для димегина, растворенного в фосфатном буфере $\mathrm{pH} 7.4$, и „Протопорфирина IX“, растворенного в диметилсульфоксиде, возбуждаемые на длине волны $\lambda_{m}=404 \mathrm{~nm} \mathrm{c} \mathrm{одинаковым}$ оптическим поглощением для обоих фотосенсибилизаторов, были получены на флуоресцентном спектрометре Shimadzu RF-5301PC. Квантовый выход флуоресценции димегина для этих условий был рассчитан с применением следующего выражения [20,21]:

$$
\Phi_{f D}=\Phi_{f \text { PPIX }} \frac{S_{D} n_{D}^{2}}{S_{\text {PPIX }} n_{\text {PPIX }}^{2}},
$$

где $S_{D}$ и $S_{\text {PPIX }}$ - интегралы площадей под кривыми спектров флуоресценции димегина и „Протопорфирина IX“,
$n_{D}$ и $n_{\text {PPIX }}$ - показатели преломления растворителей, a $\Phi_{f D}$ и $\Phi_{f \text { PPIX }}=0.16$ [22] - квантовые выходы флуоресценции димегина и „Протопорфирина IX“. Значение квантового выхода флуоресценции димегина получилось равным $0.11 \pm 0.01$.

\section{Заключение}

В результате выполненного исследования фотофизических свойств димегина, фотодитазина и радахлорина выявлена зависимость фотофизических и оптических свойств исследуемых фотосенсибилизаторов от спектров их поглощения, поскольку данный аспект весьма важен при выборе источников облучения как для фотодинамической терапии, так и флуоресцентной диагностики.

Выполнено сравнительное исследование эффективности генерации СК и интенсивности флуоресценции димегина, фотодитазина и радахлорина. Результаты показали, что димегин обладает более высокой эффективностью генерации СК, особенно при облучении источником света с длиной волны 395-405 nm. При этом у димегина отмечена и достаточно высокая интенсивность флуоресценции.

На основе полученных экспериментальных данных по измерению спектров поглощения и флуоресценции растворов димегина представлена схема его энергетических уровней.

Измерены квантовые выходы генерации СК для димегина $(0.65 \pm 0.06)$ и фотодитазина $(0.56 \pm 0.05)$ и константы тушения СК димегином $\left(2.2 \cdot 10^{7} 1 \mathrm{~mol}^{-1} \mathrm{~s}^{-1}\right)$ и фотодитазином $\left(2.5 \cdot 10^{7} 1 \mathrm{~mol}^{-1} \mathrm{~s}^{-1}\right)$. Определен квантовый выход флуоресценции для димегина $(0.11 \pm 0.01)$. Высокие квантовые выходы генерации СК и флуоресценции являются для димегина показателем возможности успешного использовании его в фотодинамической терапии и во флуоресцентной диагностике.

\section{Список литературы}

[1] Красновский А.А. мл., Егоров С.Ю., Назарова О.В., Ярцев Е.И., Пономарев Г.В. // Биофизика. 1987. Т. 32. В. 6. C. 982; Krasnovskii A.A.Jr., Yegorov S.Yu., Nazarova O.V., Yartsev Ye.I. Ponomarev G.V. // Biophysics. 1987. V. 32. N 6. P. 1069.

[2] Fickweiler S., Szeimies R.-M., Abels C., Ponomarev G.V., Hofstädter F., Wolfbeis O.S., Landthaler M. // Photodermatology, Photoimmun. Photomed. 1998. V. 14. N 3-4. P. 125.

[3] Allison R.R., Downie G.H., Cuenca R. et al. // Photodiagnosis and Photodynamic Therapy. 2004. V. 1. P. 27.

[4] Allison R.R., Sibata C.H. // Photodiagnosis and Photodynamic Therapy. 2010. V. 7. P. 61.

[5] Глаголев Н.Н., Роговина С.Ж., Соловьева А.Б., Аксенова Н.А., Котова С.Л. // Журн. физ. химии. 2006. Т. 80. № 1. C. 72.

[6] Аксенова Н.А., Тимофеева В.А., Роговина С.З., Тимашев П.С., Глаголев Н.Н., Соловьева А.Б. // Высокомолекулярные соединения. Серия Б. 2010. Т. 52. № 2. С. 314. 
[7] Glazov A.L., Semenova I.V., Vasyutinskii O.S. // J. Appl. and Laser Spectroscopy. 2015. V. 2. N 1. P. 9.

[8] Aksenova I.V., Kuznetsova R.T., Pozdnyakov I.P., Plyusnin V.F., Berezin M.B., Bumagina N.A., Jarnikova E.S., Parkhats M.V., Dzhagarov B.M. // J. Photochem. Photobiol. A. 2017. V. 344. P. 206.

[9] Zarubaev V.V., Kris'ko T.K., Kriukova E.V., Muraviova T.D. // Photodiagnosis and Photodynamic Therapy. 2017. V. 20. P. 137.

[10] Дадеко А.В., Муравьева Т.Д., Стародубцев А.М., Горелов С.И., Добрун М.В., Багров И.В., Белоусова И.М., Пономарев Г.В. // Опт. и спектр. 2015. Т. 119. № 4. С. 617; Dadeko A.V., Muraveva T.D., Starodubtsev A.M., Gorelov S.I., Dobrun M.V., Krisko T.K., Bagrov I.V., Belousova I.M., Ponomarev G.V. // Opt. Spectrosc. 2015. V. 119. N 4. P. 633-637.

[11] Киселев В.М., Кисляков И.М., Багров И.В. // Опт. и спектр. 2016. Т. 120. № 6. С. 916; Kiselev V.M., Kislyakov I.M., Bagrov I.V. // Opt. Spectrosc. 2016. V. 120. N 6. P. 859.

[12] Багров И.В., Белоусова И.М., Данилов О.Б., Киселев В.М., Соснов Е.Н. // Опт. и спектр. 2007. Т. 102. № 1. С. 58; Bagrov I.V., Belousova I.V., Danilov O.B., Kiselev V.M., Murav'eva T.D., Sosnov E.N. // Opt. Spectrosc. 2007. V. 102. N 1. P. 52.

[13] Hanf A., Läuter A., Volpp H.-R. // Chem. Phys. Lett. 2003. V. 368. P. 445.

[14] Гуринович Г.П., Севченко А.Н., Соловьев К.Н. // УФН. 1963. T. 79. № 2. C. 173.

[15] DeRosa M.C., Crutchley R.J. // Coordination Chem. Rev. 2002. V. 233-234. P. 351.

[16] Arbogast J.W., Darmanyan A.P. et al. // J. Phys. Chem. 1991. V. 95. P. $11-12$.

[17] Spiller W., Kliesch H., Wöhrle D., Hackbarth S., Röder B., Schnurpfeil G. // J. Porph. Phthalocyan. 1998. V. 2. P. 145.

[18] Belik V.P., Gadzhiev I.M., Petrenko M.V., Petrov M.A., Semenova I.V., Vasyutinskii O.S. // Chem. Phys. Lett. 2016. V. 665. P. 127.

[19] Schweitzer C., Schmidt R. // Chem. Rev. 2003. V. 103. P. 1685.

[20] Grabolle M., Spieles M., Lesnyak V., Gaponik N., Eychmüller A., Resch-Genger U. // Analytical Chemistry. 2009. V. 81. N 15. P. 6285.

[21] Würth C., Grabolle M., Pauli Ju., Spieles M., ReschGenge U. // Nature Protocols. 2013. V. 8. N 8. P. 1535.

[22] Ho C.J., Balasundaram G., Driessen W., McLaren R., Wong C.L., Dinish U.S., Attia A.B., Ntziachristos V., Olivo M. // Scientific Reports. 2014. Article ID: 5342. 